\title{
Endoscopic Endonasal Supraoptic and Infraoptic Approaches for Complex "Parasuprasellar" Lesions: Surgical Anatomy, Technique Nuances, and Case Series
}

\section{You Yuan Bao}

Endoscopic Endonasal Supraoptic and Infraoptic Approaches for Complex "Parasuprasellar" Lesions: Surgical Anatomy, Technique Nuances, and Case Series

\section{You Qing Yang}

Endoscopic Endonasal Supraoptic and Infraoptic Approaches for Complex "Parasuprasellar" Lesions: Surgical Anatomy, Technique Nuances, and Case Series

\section{Lin Zhou}

Endoscopic Endonasal Supraoptic and Infraoptic Approaches for Complex "Parasuprasellar" Lesions: Surgical Anatomy, Technique Nuances, and Case Series

\section{Shen Hao Xie}

Endoscopic Endonasal Supraoptic and Infraoptic Approaches for Complex "Parasuprasellar" Lesions:

Surgical Anatomy, Technique Nuances, and Case Series

\section{Xiao Wu}

Endoscopic Endonasal Supraoptic and Infraoptic Approaches for Complex "Parasuprasellar" Lesions:

Surgical Anatomy, Technique Nuances, and Case Series

\section{Han Ding}

Endoscopic Endonasal Supraoptic and Infraoptic Approaches for Complex "Parasuprasellar" Lesions: Surgical Anatomy, Technique Nuances, and Case Series

Jie Wu

Endoscopic Endonasal Supraoptic and Infraoptic Approaches for Complex "Parasuprasellar" Lesions: Surgical Anatomy, Technique Nuances, and Case Series

\section{Li Min Xiao}

Endoscopic Endonasal Supraoptic and Infraoptic Approaches for Complex "Parasuprasellar" Lesions: Surgical Anatomy, Technique Nuances, and Case Series

\section{Le Yang}

Endoscopic Endonasal Supraoptic and Infraoptic Approaches for Complex "Parasuprasellar" Lesions:

Surgical Anatomy, Technique Nuances, and Case Series

\section{Bin Tang}

Endoscopic Endonasal Supraoptic and Infraoptic Approaches for Complex "Parasuprasellar" Lesions: Surgical Anatomy, Technique Nuances, and Case Series 


\section{Tao Hong ( $\sim$ ht2000@vip.sina.com )}

First Affiliated Hospital of Nanchang University https://orcid.org/0000-0002-2693-8991

\section{Research Article}

Keywords: endoscopic endonasal approach, parasuprasellar area, anterior clinoid process, optic canal, internal carotid artery, surgical technique

Posted Date: October 1st, 2021

DOI: https://doi.org/10.21203/rs.3.rs-622199/v2

License: (c) (1) This work is licensed under a Creative Commons Attribution 4.0 International License. Read Full License 


\section{Abstract}

Surgical management of lesions involving the lateral area of the suprasellar region, including the lateral aspect of the planum sphenoidale and a tight junction region of the optic canal (OC), the anterior clinoid process (ACP), and the internal carotid artery (ICA) and its dural rings, is extremely challenging. Here, the authors introduce two novels endoscopic endonasal supraoptic (EESO) and endoscopic endonasal infraoptic (EEIO) approaches to access these regions, namely, "parasuprasellar" area. Surgical simulation of the EESO and EEIO approaches to the parasuprasellar area was conducted in 5 silicon-injected specimens. The same techniques were applied in 12 patients involving the parasuprasellar area.The EESO and EEIO approaches can be used independently or in combination, but are more often employed as a complement to the endoscopic endonasal midline approach and transcavernous approach. In clinical application, the EESO and EEIO approaches were successfully performed in 12 patients harboring tumors and multiple aneurysms involving the parasuprasellar area. Gross total and subtotal tumor resection were achieved in 9 patients and 1 patient, respectively. For two patients with multiple aneurysms, the lesions were clipped selectively according to location and size. Visual acuity improved in 7 patients, remained stable in 4 , and deteriorated in only 1 . No postoperative intracranial infection or ICA injury occurred in this series. The EESO and EEIO approaches can be combined with the current endoscopic endonasal midline approach and transcavernous approach to remove extensive pathologies involving the intrasellar, suprasellar, sphenoid, and cavernous sinuses and even bifurcation of the ICA.

\section{Introduction}

With advances in surgical anatomy and endoscopic technology, the endoscopic endonasal approach (EEA) has been widely applied for ventral skull base lesions over the last decades.[5, 14, 15] Furthermore, this approach has been expanded to the lateral skull base, accompanied by the introduction of endoscopic transpterygoid route, such as the cavernous sinus (CS), pterygopalatine fossa and infratemporal fossa. $[2,6,10,11,13,24]$ The anatomy and related surgical nuances of these complex skull base areas have been well documented in a considerable amount of literature. Nevertheless, few reports exist on the detailed anatomy of the lateral area of the suprasellar region, including the lateral aspect of the planum sphenoidale and a tight junction region of the optic canal (OC), the anterior clinoid process (ACP), and the internal carotid artery (ICA) and its dural rings that fix its courses.[1,9] There are essentially two reasons for such limited data: 1 ) limited access to these regions due to obstruction of vital neurovascular structures such as the optic nerve (ON) and ICA; 2 ) these regions are considered offlimits due to the lateral-seated location and intrinsic anatomical complexity. In fact, it is difficult to imagine the existence of such high density of neurovascular and osseous as well as dural structures in such a narrow anatomic space.

Although not common, some different pathologies can afflict these regions, including primary lesions, such as ACP meningiomas and paraclinoid aneurysms, but more secondary tumors spread, such as tuberculum sellae meningiomas, invasive pituitary adenomas and craniopharyngiomas, from nearby regions. Pathologies encountered in these areas are typically intra- and extracranially. Moreover, these 
lesions tend to displace the $\mathrm{ON}$ from above and/or below, erode osseous and dural structures, and even encase the ICA and its bifurcation. Therefore, effective resection of these lesions poses a considerable challenge, even for skilled and experienced neurosurgeons.

Several traditional transcranial approaches (TCAs), including the standard or extended pterional approach,[20, 22] orbital-zygomatic approach[3] and supraorbital approach,[21] for accessing lesions in these areas have been described. Although TCAs can be a good alternative for subdural lesions, extradural lesions involving the intrasellar, sphenoid sinus and even CS are extremely difficult to manage because surgical corridors are inconsistent with the axis of tumor growth. In addition, inevitable brain retraction, extensive bone removal, and easy damage to important neurovascular elements make TCAs less favorable options.

In contrast, the EEA provides a direct corridor to access extradural lesions, with the advantage of easy removal of extensively involved osseous architectures and dural attachments. Additionally, a corridor to the subdural lesions is established when these lesions are removed. Most importantly, EEA allows for early identification and control of the paraclinoidal ICA, which is the main structure that must be crossed to expand laterally into these regions. These advantages are particularly promising for treating lesions involving these areas. Nevertheless, there are few reports regarding the endoscopic anatomy and how to effectively manage lesions involved in these areas. $[1,9]$

For this reason, we sought to undertake a thorough anatomical description of the lateral aspect of the planum sphenoidale and a tight junction region of the OC, ACP, and ICA and its dural rings. These regions are located on the lateral area of the suprasellar region, the "parasuprasellar" area. Building on our detailed dissection, we introduce two novels endoscopic endonasal supraoptic (EESO) and endoscopic endonasal infraoptic (EEIO) approaches to access the parasuprasellar area. Indications and nuances of these approaches in treating 12 patients with tumors and aneurysms involving this area are also presented.

\section{Methods}

\section{Anatomical Dissection}

Five embalmed and injected adult cadaveric heads were used for endoscopic and microsurgical dissection. The anatomy research was approved by our institutional ethics committee. Endoscopic endonasal anatomical dissections were performed using rod lens endoscopes (4-mm diameter, 18-cm length, $0^{\circ}$ and $30^{\circ}$, Karl Storz). An extended EEA to the sella, parasellar and suprasellar areas, involving wide sphenoidotomy, posterior ethmoidectomy, and posterior septectomy, followed by a transpterygoid approach, was performed for all cadaveric heads in a stepwise manner, as previously described.[14, 15, 25] All intrasphenoidal landmarks were exposed, including the sella, tuberculum sellae, optic protuberances, carotid protuberances, medial optocarotid recesses (MOCR) and lateral optocarotid recesses (LOCR). The posterior ethmoidal artery (PEA) was also skeletonized. 
We defined the parasuprasellar area as a quadrangular space, and its main contents included the $O N$, the ICA and its proximal and distal dural rings, the ophthalmic artery (OA), and the ACP. The PEA is defined as the upper boundary of the parasuprasellar area. The inferior boundary is formed by the horizontal connection between the inferior edge of the LOCR and MOCR. The medial boundary is the vertical connection between the medial edge of the MOCR and the PEA, and the lateral boundary is the vertical connection between the lateral edge of the LOCR and the PEA. In addition, we divided the parasuprasellar area into 2 compartments based upon the $\mathrm{ON}$ : supraoptic and infraoptic compartments (Fig. 1A). The EESO and EEIO approaches were performed to access the supraoptic and infraoptic regions, respectively.

Particular attention should be paid to the anatomy of the parasuprasellar area and its vicinity from an endoscopic perspective as well as to the stepwise surgical techniques related to the safe dissociation of the $\mathrm{ON}$ and $\mathrm{OA}$. After completing the endonasal procedures, the extent of bone and dural removal from the parasuprasellar area was further evaluated from the intracranial superior view. Several anatomic parameter measurements were also measured and recorded.

\section{Patient Population}

From January 2016 to March 2020, we retrospectively reviewed 12 patients with lesions invading the parasuprasellar area and for whom the EESO and EEIO approaches were performed either alone or in combination. T1/T2WI and Gd-enhanced T1WI were performed in 10 patients with tumors, and contrastenhanced postoperative MRI was performed as follow-up on postoperative days 1 and at 3 months after surgery. The remaining two patients with multiple aneurysms underwent pre- and postoperative cerebrovascular examinations, including CT angiography and digital subtraction angiography (DSA). All patients also underwent preoperative thin-slice CT scans to evaluate the extent of OC and ACP involvement. Preoperative BOT was performed to evaluate whether collateral circulation could be compensated; if poor, an endovascular stent or bypass would be prepared. Intraoperative electrophysiological monitoring, particularly visual evoked potentials (VEPs), was used routinely throughout the procedure. Intraoperative neuronavigation and Doppler ultrasound were also applied to determine the exact course of the ICA. Additionally, the paraclival ICA was exposed in advance for proximal control. Special attention was given to the ophthalmological evaluation, including visual acuity and visual field, and limitations of ocular motility were observed by ophthalmologist for all patients preoperatively and 3 to 6 months after surgery. All medical records were reviewed and analyzed retrospectively, including symptoms, neuroimaging, intraoperative video, technical nuances, and surgical outcomes (Table 1).

\section{TABLE 1. Summary characteristics and outcomes of all 12 clinical cases}




\begin{tabular}{|c|c|c|c|c|c|c|c|c|c|c|c|c|c|c|c|}
\hline \multirow{2}{*}{$\begin{array}{l}\text { Case } \\
\text { No. }\end{array}$} & \multirow{2}{*}{ Age/Sex } & \multirow{2}{*}{ Size(cm) } & \multirow{2}{*}{ Diagnosis } & \multicolumn{2}{|c|}{ Preop } & \multirow{2}{*}{ Other Symptoms } & \multirow{2}{*}{$\begin{array}{c}\text { ICA, ACA, MCA } \\
\text { Involvement }\end{array}$} & \multirow{2}{*}{$\begin{array}{r}\text { Previous } \\
\text { Treatment }\end{array}$} & \multirow{2}{*}{$\begin{array}{c}\text { Surgical } \\
\text { Approach }\end{array}$} & \multirow{2}{*}{$\begin{array}{c}\text { Anterior } \\
\text { Clinoidectomy }\end{array}$} & \multirow{2}{*}{ EOR } & \multicolumn{2}{|c|}{ Postop } & \multirow{2}{*}{ Complications } & \multirow{2}{*}{$\begin{array}{c}\text { Follow- } \\
\text { Up(months) }\end{array}$} \\
\hline & & & & Visual Acuity & Visual Field & & & & & & & Visual Acuity & Visual Field & & \\
\hline 1 & $56 \mathrm{~F}$ & $2.1 \times 1.9 \times 1.7$ & Lt ACP meningioma & Visual loss (lit) & Upper hemianopsia & Dizzy & No & None & $\mathrm{TPA}+\mathrm{SOA}$ & No & GTR & Improvement & Normal & None & 56 \\
\hline 2 & $25 / \mathrm{F}$ & $2.5 \times 1.9 \times 1.4$ & Rt ACP meningioma & Visual loss (tr) & $\begin{array}{l}\text { Rt temporal } \\
\text { hemianopsia }\end{array}$ & Headache & Yes, all attached & $\begin{array}{l}\text { Pterional } \\
\text { approach }\end{array}$ & $\mathrm{TMA}^{*}+\mathrm{IOA}$ & Yes & GTR & $\begin{array}{c}\text { Worse (rt), } \\
\text { unchanged (lt) }\end{array}$ & $\begin{array}{l}\text { Rt temporal } \\
\text { hemianopsia }\end{array}$ & None & 50 \\
\hline 3 & $56 \mathrm{~F}$ & $2.1 \times 1.8 \times 1.7$ & Lt ACP meningioma & Normal & Normal & Dizzy & Yes, all attached & None & $\mathrm{TMA}+\mathrm{SOA}+\mathrm{IOA}$ & No & GTR & Stable & Normal & None & 36 \\
\hline 4 & $37 / F$ & $3.0 \times 1.7 \times 1.4$ & Lt ACP meningioma & Visual loss (lt) & $\begin{array}{l}\text { Lt temporal } \\
\text { hemianopsia }\end{array}$ & None & Yes, all encased & $\begin{array}{l}\text { Pterional } \\
\text { approach }\end{array}$ & $\begin{array}{c}\mathrm{TMA}+\mathrm{TPA}+\mathrm{TCA} \\
+\mathrm{SOA}+\mathrm{IOA}\end{array}$ & Yes & STR & Stable & $\begin{array}{l}\text { Lt temporal } \\
\text { hemianopsia }\end{array}$ & CNIII pasly & 45 \\
\hline 5 & $12 \mathrm{M}$ & $2.8 \times 3.1 \times 3.9$ & $\begin{array}{l}\text { Osteogenic } \\
\text { meningioma }\end{array}$ & Visual loss & Lt amaurosis & None & No & None & $\begin{array}{c}\mathrm{TMA}+\mathrm{TPA}+\mathrm{SOA} \\
+\mathrm{IOA}\end{array}$ & Yes & GTR & $\begin{array}{c}\text { Marked } \\
\text { improvement }\end{array}$ & $\begin{array}{l}\text { Lt temporal } \\
\text { hemianopsia }\end{array}$ & Transient DI & 18 \\
\hline 6 & $45 / F$ & $3.7 \times 4.0 \times 3.9$ & Pituitary adenoma & Visual loss & $\begin{array}{l}\text { Lt temporal } \\
\text { hemianopsia }\end{array}$ & Headache & $\begin{array}{l}\text { Yes, ICA and ACA } \\
\text { encased }\end{array}$ & None & $\begin{array}{c}\mathrm{TMA}+\mathrm{TPA}+\mathrm{TCA} \\
+\mathrm{SOA}+\mathrm{IOA}\end{array}$ & No & GTR & Stable & $\begin{array}{l}\text { Lt temporal } \\
\text { hemianopsia }\end{array}$ & CSF leak & 30 \\
\hline 7 & $52 \mathrm{~F}$ & $3.5 \times 2.7 \times 2.9$ & Pituitary adenoma & Visual loss & $\begin{array}{l}\text { Rt temporal } \\
\text { hemianopsia }\end{array}$ & None & $\begin{array}{l}\text { Yes, ICA encased, } \\
\text { ACA and MCA attached }\end{array}$ & $\begin{array}{c}\text { Endonasal } \\
\text { endoscopic } \\
\text { approach }\end{array}$ & $\begin{array}{c}\mathrm{TMA}+\mathrm{TPA}+\mathrm{TCA} \\
+\mathrm{SOA}+\mathrm{IOA}\end{array}$ & Yes & GTR & Improvement & Normal & $\begin{array}{l}\text { Panhypopituitarism } \\
\text { Transient DI }\end{array}$ & 22 \\
\hline$s$ & $56 \mathrm{M}$ & $4.5 \times 2.7 \times 3.0$ & Pituitary adenoma & Visual loss (tr) & $\begin{array}{c}\text { Bitemporal } \\
\text { hemianopsia }\end{array}$ & $\begin{array}{l}\text { Headache, } \\
\text { hypomnesis }\end{array}$ & $\begin{array}{c}\text { Yes, ICA encased, } \\
\text { ACA attached }\end{array}$ & $\begin{array}{c}\text { Endonasal } \\
\text { microscope } \\
\text { approach }\end{array}$ & $\begin{array}{c}\mathrm{TMA}+\mathrm{TPA}+\mathrm{TCA} \\
+\mathrm{SOA}+10 \mathrm{~A}\end{array}$ & No & GTR & $\begin{array}{c}\text { Marked } \\
\text { Improvement }\end{array}$ & Normal & None & 29 \\
\hline 9 & $47 / \mathrm{F}$ & $\begin{array}{c}\text { It paraclinoid: } \\
0.7 \times 0.8 \\
\text { It ophthalmic: } \\
0.4 \times 0.3 \\
\text { It cav-ICA: } 0.5 \times 0.4\end{array}$ & $\begin{array}{l}\text { Multiple aneurysms: } \\
\text { It paraclinoid, it } \\
\text { ophathalmic, it } \\
\text { cav-ICA }\end{array}$ & Normal & Normal & Headache & $\mathrm{NA}$ & None & $\mathrm{TMA}+\mathrm{TPA}+\mathrm{IOA}$ & Yes & $\begin{array}{l}\text { Clipping of it } \\
\text { paraclinoid, it } \\
\text { ophathalmic } \\
\text { aneurysms }\end{array}$ & Stable & Normal & None & 58 \\
\hline 10 & $62 \mathrm{~F}$ & $\begin{array}{c}\text { It paraclinoid: } \\
0.75 \times 0.42 \\
\text { rt paraclinoid: } \\
2.26 \times 2.17 \\
\text { Acom: } 0.4 \times 0.3\end{array}$ & $\begin{array}{c}\text { Multiple aneurysms: } \\
\text { It paraclinoid, rt } \\
\text { paraclinoid, Acom }\end{array}$ & Visual loss & Normal & Dizzy & $\mathrm{NA}$ & None & $\mathrm{TMA}+\mathrm{IOA}$ & No & $\begin{array}{l}\text { Clipping of } 1 \mathrm{t} \\
\text { paraclinoid, } \\
\text { Acom } \\
\text { aneurysms }\end{array}$ & $\begin{array}{l}\text { Marked } \\
\text { improtement }\end{array}$ & Normal & None & 44 \\
\hline 11 & $30 \mathrm{M}$ & $2.3 \times 2.2 \times 1.9$ & Craniopharyngioma & Visual loss (rt) & Lower marginal field & None & Yes, all encased & $\begin{array}{l}\text { Subfroutal } \\
\text { approach, } \\
\text { V-P shunting }\end{array}$ & $\mathrm{TMA}+\mathrm{SOA}+\mathrm{IOA}$ & No & GTR & Improvement & Rt hemianopsia & $\begin{array}{c}\text { Hypothyroidism } \\
\text { DI }\end{array}$ & 26 \\
\hline 12 & $37 / F$ & $1.8 \times 1.4 \times 1.0$ & $\begin{array}{l}\text { Meningeal IgG4- } \\
\text { related disease }\end{array}$ & Visual loss ( $r t$ ) & $\begin{array}{l}\text { Rt temporal } \\
\text { hemianopsia }\end{array}$ & None & No & None & $\mathrm{TMA}+\mathrm{SOA}+\mathrm{IOA}$ & Yes & GTR & Improvement & Normal & CNII pasly & 52 \\
\hline
\end{tabular}

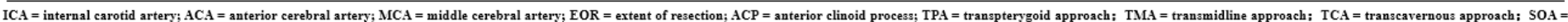

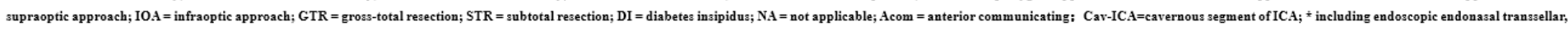
transtuberculum, transplanumh and transclivus approaches.

\section{Results}

\section{EESO Approach to the Supraoptic Region}

Stage 1: Recognition and Exposure of the Supraoptic Recess

After undergoing an initial extended EEA, the PEA located in its osseous canal is identified and serves as the upper boundary of the supraoptic region; the artery can be ligated and transected to facilitate lateral mobilization. The supraoptic recess is pyramid-shaped, with its base abutting the sphenoid sinus and apex corresponding intracranially to the body of the lesser sphenoid wing (Fig. 2A).[9] The supraoptic recess needs to be identified and sufficiently delineated because its removal is one of the key steps to achieve further lateral extension over the planum sphenoidale.

Stage 2: Removal of the Medial Portion of the Lesser Sphenoid Wing and OC Unroofing

During this stage, the base of the supraoptic recess is drilled with a small diamond burr, proceeding deeply in a medial-to-lateral direction toward the body of the lesser sphenoid wing. As a consequence, the most medial portion of the lesser sphenoid wing overlying the orbit is exposed and progressively drilled out. However, removal of the lateral portion of the lesser sphenoid wing is limited inferiorly by the intracanalicular portion of the $\mathrm{ON}$ and the superior aspect of the medial orbital walls, which serves as the 
main anatomical landmark of the superolateral boundary of this exposure (Fig. 2B). Afterward, the roof wall of OC is drilled.

Stage 3: Resection of the Lateral Dura of the Planum Sphenoidale and Exposure of the Orbital Gyrus

The dura mater of the planum sphenoidale is opened in a posterior-to-anterior direction, after which the gyrus rectus of the frontal lobes and the olfactory nerve are visible at this level. The residual lateral part of the dura mater of the planum sphenoidale can be safely removed using an outward-facing Kerrison rongeur. This maneuver permits visualization of the medial orbital gyrus, anterior orbital gyrus and post orbital gyrus of the frontal lobes (Fig. 2C). At this time, the distances from the lateral edge of the olfactory nerve to the outermost edge of the orbital gyrus are measured with a ruler (Table 2).

Table 2

Relevant measurements

\begin{tabular}{|llll|}
\hline Measurement & $\begin{array}{l}\text { Mean } \pm \\
\text { SD,mm(right]n } \\
=5)\end{array}$ & $\begin{array}{l}\text { Mean } \pm \text { SD, } \\
\text { mm(left, }=5)\end{array}$ & $\begin{array}{l}\text { Mean } \pm \\
\text { SD,mm(total[n } \\
=10)\end{array}$ \\
\hline $\begin{array}{l}\text { The length of the three sides of the ACP } \\
\text { triangle: }\end{array}$ & & & \\
\hline superomedial to superolateral vertices & $4.30 \pm 0.57$ & $4.40 \pm 0.65$ & $4.35 \pm 0.58$ \\
\hline superomedial to inferior vertices & $4.10 \pm 0.55$ & $4.20 \pm 0.45$ & $4.15 \pm 0.47$ \\
\hline $\begin{array}{l}\text { superolateral to inferior vertices } \\
\text { The lateral edge of the olfactory nerve to the } \\
\text { outermost edge of the orbital gyrus }\end{array}$ & $3.80 \pm 0.27$ & $3.90 \pm 0.42$ & $3.85 \pm 0.34$ \\
\hline
\end{tabular}

\section{EEIO Approach to the Infraoptic Region}

Stage 1: Removal of the Anterior Wall of the OC and Exposure of the Intracranial ON

After the bone of the anterior wall of the $\mathrm{OC}$ is removed in a medial-lateral direction up to the orbit apex, the dura overlying the intracranial $O N$ is incised longitudinally to expose the origin of the OA. Of note, the most common relationship of the origin of the OA to the intracranial ON is an inferomedial location; thus, opening the dura through a cut parallel to the $\mathrm{ON}$ in its upper half reduces the risk of damaging the artery. $[17,23]$ To gain the working space in the medial region of the paraclinoidal ICA, the diaphragm is incised toward the medial part of the distal dural ring (DDR). Following this, intradural exploration of the main neurovascular structures is performed. The pituitary stalk, superior hypophyseal artery (SHA) and its branches are exposed by gently lifting the ipsilateral ON (Fig. 3C). Sliding deeper, the posterior communicating artery (PcomA) and the $\mathrm{A} 1$ segments of the anterior cerebral artery are identified using the space between the SHA and the ON (Fig. 3D).

Stage 2: Drilling of the Optic Strut and Dissociation of the OA 
Surgery in the lateral compartment of the paraclinoidal ICA requires removal of the optic strut, which corresponds to the LOCR from the endonasal perspective.[19] Three vertices of this recess (resembling a triangle in shape) are identified: the superomedial, superolateral, and inferior vertices. The distance between each vertex of the LOCR is measured (Supplemental Table 1). With regard to how to safely remove the three vertices in turn to the base of the ACP, we have specifically discussed the relevant anatomical details and surgical nuances in a previous publication.[26] Once drilling of the optic strut is concluded (Fig. 3E), the DDR is opened to further safely dissociate the OA. Next, proper exposure of the $\mathrm{ON}$ and $\mathrm{OA}$ surrounded by the dural sheath is performed. At this stage, the course of the precanalicular $\mathrm{ON}$ and $\mathrm{OA}$ are entirely exposed (Fig. 3F). This maneuver aims to separate the $\mathrm{ON}$ from the $\mathrm{OA}$, thus widening the surgical corridor of the infraoptic approach. The main structures are identified, including the PcomA, the anterior choroidal artery and its branches into the anterior perforating substance, the oculomotor nerve passing between the posterior cerebral artery and superior cerebellar artery into the CS, and the bifurcation of the ICA (Fig. $3 \mathrm{G}$ and $\mathrm{H}$ ).

Stage 3: Removal of the ACP and Severing of the OA

The ACP is now only connected to part of the lesser sphenoid wing. By using this ACP triangle space and following gentle medial mobilization of paraclinoidal ICA, drilling and curettage of the base and tip of the ACP becomes feasible (Fig. 3I). However, this step is performed with extreme care to avoid injury to the ICA, OA, ON and oculomotor nerve, and tailored bone drilling is strongly suggested according to diseasespecific management. Once removal of the ACP tip is achieved, the dura of the inferior surface of the ACP is incised with angled scissors or coagulated. At this moment, the sylvian cistern is visible, and M1 is exposed between the frontal and temporal lobes; more laterally, the middle cerebral artery bifurcation is observed at the level of its insular portion (Fig. 3K). Some perforating vessels from M1 are also identified. At the end, the $\mathrm{OA}$ is transected, and the operating space of the infraoptic approach is further enlarged (Fig. 3L).

\section{Combined EESO and EEIO Approaches for the Parasuprasellar Area}

After completing the above step-by-step dissection, combined EESO and EEIO approaches for accessing the parasuprasellar area were performed, as shown in Fig. 4. It should be emphasized that the EESO and EEIO approaches can be used either alone or in combination; they can also be combined with the endoscopic endonasal midline approach (transsellar/transtuberculum/transplanumh) and trancavernous approach according to the disease-specific location (Fig. 1B-D).

\section{EESO and EEIO Approaches: Case Series}

The EESO and EEIO approaches were successfully performed either alone or in combination for 12 patients harboring tumors and aneurysms involving the parasuprasellar area (Table 1). The mean patient age was 42.9 years (range 12-62 years); there were 3 males and 9 females. The most common presenting symptom was visual deficit, including visual loss and visual field defects. Other symptoms 
were headache, dizziness, and hypomnesis. Three patients had previously undergone TCA, and 2 patients underwent an endonasal (microscope or endoscopic) approach at other institutions. The final diagnoses were meningiomas in 5 patients, pituitary adenoma in 3, multiple aneurysms in 2 patients, and meningeal IgG4-related disease and craniopharyngioma in 1 patient each. Gross total tumor resection was achieved in 9 patients; subtotal resection was achieved in 1 patient. There were 2 patients with multiple aneurysms. One case of anterior communication and paraclinoid aneurysms involved clipping via a pure EEIO approach; a contralateral giant paraclinoid aneurysm was secondarily embolized at 2 months after the operation. The other patient harbored ophthalmic and paraclinoid aneurysms that were also clipped through the EEIO approach, though an intracavernous aneurysm was left untreated due to its location and size. Postoperative visual acuity improvement occurred in 7 patients, remained unchanged in 4 , and deteriorated in 1 patient in the right eye. The postoperative visual field was normal in 7 patients, whereas 5 still had unilateral temporal hemianopsia. Two patients experienced transient diabetes insipidus (DI), and 1 patient had new postoperative panhypopituitarism that had normalized by the 3-month follow-up. One patient experienced permanent $\mathrm{DI}$ and hypothyroidism, and postoperative hormone replacement therapy was required in the follow-up period. Postoperative CSF leakage occurred in 1 patient, and endoscopic endonasal repair was performed. Postoperative oculomotor nerve palsy developed in 2 patients; fortunately, it had resolved completely in one patient by the $1 \mathrm{st}$ month follow-up, and the other was significantly improved at the 6th month follow-up. No postoperative intracranial infection or ICA injury occurred in this series.

\section{Discussion}

Skull base pathologies encompassing the suprasellar lateral area, including the lateral aspect of the planum sphenoidale and a tight junction region of the OC, the ACP, and the ICA and its dural rings, still pose a unique surgical challenge for neurosurgeons in terms of subsequent morbidity and achievement of gross total resection. $[1,12,18,20,26]$ These pathologies typically involve intra- and extracranially, tend to displace the $\mathrm{ON}$ from above and/or below, erode osseous and dural structures, and even involve the ICA bifurcation. Hence, TCAs for complete resection of these lesions have a high potential morbidity, even for skilled and experienced neurosurgeons. Today, endoscopy, which offers a wider, close-up view of the surgical field, is used broadly in skull base surgery. Although it has the disadvantage of increasing the rate of CSF leakage, potential advantages of EEA compared to conventional TCAs include avoiding brain retraction, improved visualization, better protection of surrounding neurovascular structures, and shorter hospital stay. $[5,7,8,14-16]$ These advantages are similar when comparing the EEA and different TCAs for lesions involving the lateral area of the suprasellar region. The EEA not only provides the most straightforward surgical route parallel to the growth axis of the tumor but also, most importantly, allows for better control of the paraclinoidal ICA, which constitutes a lateral barrier to directly approaching these regions through the sphenoid sinus. However, the intricate anatomical complexity and lack of anatomical detail suitable for surgical exploration make these regions among the most challenging areas to approach. 
In this paper, we describe the surgical anatomy of the lateral area of the suprasellar region from the endoscopic perspective, termed the "parasuprasellar" area. Moreover, we introduce EESO and EEIO approaches to access this complex area. The same techniques were applied in 12 consecutive patients harboring tumors and aneurysms involving the parasuprasellar area. To the best of our knowledge, this is the first report on the EESO and EEIO approaches

\section{Approach Selection and Technical Considerations}

Our results validate that the EESO and EEIO approaches can effectively manage lesions involving the parasuprasellar area, as well demonstrated in our illustrations (Figs. 5-11). In our experience, when tumors simultaneously invade the intrasellar, suprasellar and lateral to the parasuprasellar area, such as pituitary adenomas or craniopharyngiomas, the EEIO approach should be considered first. If the tumor is not safely exposed or still has an invisible portion, even after pulling it downward, the EESO approach should be selected to allow for additional exposure of the lateral tumor. When the lesion originates in the parasuprasellar area, such as ACP meningiomas or paraclinoid aneurysms, the EEIO approach can also be considered first to remove the lesion on the medial or lateral side of the paraclinoidal ICA. Similarly, if the lesion cannot be completely removed through the corridor below the ON, a combined EESO approach can be applied in most cases. It must be emphasized, however, that not all lesions involving this area are indications for EESO and EEIO approaches. Indeed, a primary TCA or staged operation may be indicated when the lesion involves the intracranial to the parasuprasellar area and is mainly located subdurally.

Of note, the use of the EESO or EEIO approach alone is rather rare and most often requires a combination of the endoscopic endonasal midline approach and/or transcavernous approach. We can choose from different combinations according to the size and location of the lesion(s). For example, the transtuberculum/transplanum approach can be conveniently combined with the single EESO approach to provide better access to anterior cranial fossa meningiomas with lateral extension (case 1). Similarly, the combination of the transcavernous approach and EEIO approach has the potential for achieving complete resection of ACP meningiomas or pituitary adenomas involving the CS (cases 4, 6, 7 and 8). The EESO and EEIO approaches can be used as a complement to the midline approach and transcavernous approach and are extremely useful to access extensive pathologies for more complete resection while limiting morbidity.

\section{Graduated Stepwise EEIO Approach}

In our practice, the EEIO is a graduated, stepwise approach based largely on the lesion location, size and extent. Our anatomy and clinical cases demonstrate how to assemble multiple surgical corridors to provide personalized access to complex parasuprasellar lesions. In Case 10, in which the left paraclinoid aneurysm was located just below the $\mathrm{ON}$, successful clipping of the aneurysm was achieved using a pure EEIO approach (Fig. 6).

Regarding Case 2, we found during the operation that a recurrent ACP meningioma was severely adhered to the ON and ICA and extended into the right OC. Thus, anterior clinoidectomy was applied, and the 
tumor tightly attached to the ACP and the ICA bifurcation was completely removed (Fig. 7). It should be noted, however, that complete anterior clinoidectomy is not mandatory and that the extent of bony removal should be tailored to each case based on intraoperative need. If only the lateral region of the paraclinoidal ICA needs to be exposed or to obtain distal vascular control, partial anterior clinoidectomy should be considered; however, complete anterior clinoidectomy should be performed if the tumor involves the ACP and causes evident hyperplasia or the lesion has extended the ICA bifurcation or even more. Such resection can reduce the risk of tumor recurrence. Most importantly, a corridor accessing the lateral region of the supraclinoidal ICA is established while removing the involved ACP and the dura that envelops it. Nonetheless, this technique can only be implemented by experienced surgeons due to the complicated procedures and potential risks.

In Case 9, a lateral projecting paraclinoid aneurysm was encountered. In view of its position and orientation, we first performed anterior clinoidectomy to expose the lateral region of the paraclinoidal ICA. Then, the OA was dissociated and temporarily clipped, but the VEP was changed, which indicates that severing of the OA would lead to serious visual impairment (Fig. 8E and H). Finally, we attempted to expose the aneurysm neck between the $\mathrm{OA}$ and $\mathrm{ON}$ and successfully clipped the aneurysm through the ACP triangle (created by anterior clinoidectomy) (Fig. 8F and G).

In Case 4, the tumor involved the intrasellar, suprasellar, CS, and encased ICA and its bifurcation. The optic strut was drilled first, and the OA completely wrapped by the tumor was selectively dissected to further remove the hyperplastic ACP (Fig. 9F-H). Thus, the tumor on the medial and lateral region of the supraclinoidal ICA can be completely removed via an enlarged EEIO corridor (Fig. 9I and J). In our case series, only this case in which the OA was sacrificed occurred when preoperative DSA showed that the OA was not visible and the patient's intraoperative VEP stabilized. As expected, the patient's vision remained stable after surgery.

\section{Visual Outcomes}

The special location of such lesions is often responsible for vision loss related to intracranial and/or intracanalicular $\mathrm{ON}$ involvement. Ten patients in our series presented with varying degrees of vision loss; thus, improvement and preservation of visual function is a priority for this surgery. Remarkably, in our series, visual improvement occurred in 7 patients but was unchanged in 4, and only 1 patient with recurrent ACP meningioma developed visual deterioration. This demonstrates that gentle pulling of the ON during resection will hardly affect visual function under VEP monitoring. Postoperative visual deterioration has been mainly related to injury of the subchiasmatic perforators, providing the main blood supply to the optic chiasma.[4] Accordingly, the potential risk of injuring visual acuity may not be increased by extra manipulation in the supraoptic region. Furthermore, while applying the EEIO approach, endoscopy provides early and direct visualization of the subchiasmatic perforators, allowing for adequate dissection and protection. Last but most importantly, this approach allows for direct $270^{\circ}$ decompression of the intracanalicular ON[1] and prompt removal of the involved dura and hyperostotic bone. Nevertheless, as mentioned above, these procedures must be carried out in an extremely delicate and careful manner. When removing bone, the eggshelling technique with continuous irrigation of saline 
must be followed to prevent thermal injury to the ON. We believe that if sufficient decompression is performed without the risk of further injury, vision problems may be reversed.

\section{Limitations of the Study}

The current study has several limitations that need to be considered. First, although no ICA or ON injury occurred in our series, they are still our primary concern when managing parasuprasellar lesions. Second, cadaveric specimens are useful models to investigate surgical approaches, but they do not fully capture the clinical environment. Indeed, these corridors are relatively narrow in individuals who do not harbor such lesions. Finally, the learning curve is extremely steep and requires a high level of expertise in comprehensive skull base surgery, including both microsurgical cerebrovascular and endoscopic skills. Consequently, practice in the cadaver laboratory is mandatory to develop familiarity with these precise and meticulous operations before they are applied clinically.

\section{Conclusions}

Based on our anatomic and surgical results, the EESO and EEIO approaches offer a unique treatment option for well-selected lesions involving the parasuprasellar area. The approaches can be combined with an endoscopic endonasal midline approach and a transcavernous approach to remove extensive pathologies involving the intrasellar, suprasellar, sphenoid, and cavernous sinuses and even the bifurcation of the ICA. Our work for the first time pushes the boundary of the EEA lateral to the supraclinoidal ICA and ON and adds new territories (parasuprasellar area) to the lateral skull base.

\section{Declarations}

Funding information $₫$ This study was supported by the National Natural Science Foundation of China (grant nos. 82060246 and 81460381), the Ganpo555 Engineering Excellence of Jiangxi Science and Technology Department (2013), and the Key Research and Invention Plan of Jiangxi Science and Technology Department (20192BBG70026). Conflicts of Interest: The authors have no conflicts of interest to declare that are relevant to the content of this article. Availability of data and material: All data generated or analyzed during this study are included in this published article and its supplementary information files. Code availability: Not applicable. Ethics approval: Anatomical study with cadaver heads and human subject approval was obtained from the Institutional Ethics Committee of the First Affiliated Hospital of Nanchang University prior to the commencement of the study. The study was performed in accordance with the ethical standards as laid down in the 1964 Declaration of Helsinki and its later amendments. Consent to participate: Informed consent was obtained from all individual participants included in the study. Consent for publication: All the authors gave consent for publication of the article. Authors' contributions: Tao Hong contributed to the study conception and design. Material preparation and data collection were performed by YouYuan Bao, YouQing Yang and Lin Zhou. Analysis of the data

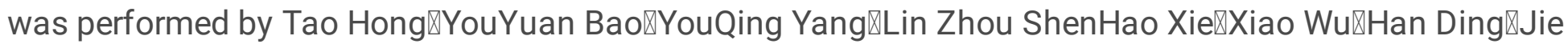
Wu囚Li Min Xiao囚Le Yang and Bin Tang. The first draft of the manuscript was written by YouYuan Bao. All 
authors commented on previous versions of the manuscript. All authors read and approved the final manuscript. Acknowledgments $₫$ We express our sincere appreciation to Miss Jing Liu for the illustration.

\section{References}

1. Abhinav K, Acosta Y, Wang WH, Bonilla LR, Koutourousiou M, Wang E, Synderman C, Gardner P and

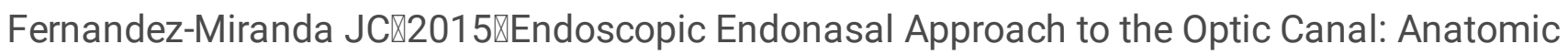
Considerations and Surgical Relevance. Neurosurgery11 Suppl 3:431-45, discussion 445-6

2. Alfieri A, Jho HD, Schettino R and Tschabitscher M®2003囚Endoscopic endonasal approach to the pterygopalatine fossa: anatomic study. Neurosurgery52:374-78, discussion 378-80

3. Attia M, Umansky F, Paldor I, Dotan S, Shoshan Y and Spektor S $₫ 2012 \rrbracket$ Giant anterior clinoidal meningiomas: surgical technique and outcomes. J Neurosurg117:654-65

4. BLUNT MJ, STEELE EJ囚1956冈The blood supply of the optic nerve and chiasma in man. J Anat90:486-93

5. Cavallo LM, Messina A, Cappabianca P, Esposito F, de Divitiis E, Gardner P and Tschabitscher M

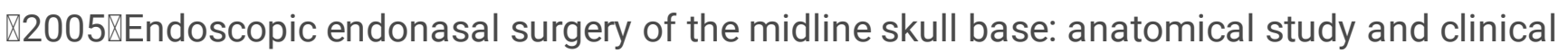
considerations. Neurosurg Focus19:E2

6. Cavallo LM, Messina A, Gardner P, Esposito F, Kassam AB, Cappabianca P, de Divitiis E and Tschabitscher $\mathrm{M} \otimes 2005 \varangle \mathrm{Extended}$ endoscopic endonasal approach to the pterygopalatine fossa: anatomical study and clinical considerations. Neurosurg Focus19:E5

7. de Divitiis E, Cavallo LM, Cappabianca P and Esposito F囚2007هExtended endoscopic endonasal transsphenoidal approach for the removal of suprasellar tumors: Part 2. Neurosurgery60:46-58, discussion 58-9

8. Dehdashti AR, Ganna A, Witterick I and Gentili F®2009هExpanded endoscopic endonasal approach for anterior cranial base and suprasellar lesions: indications and limitations. Neurosurgery64:677-87, discussion 687-9

9. Di Somma A, Torales J, Cavallo LM, Pineda J, Solari D, Gerardi RM, Frio F, Ensenat J, Prats-Galino A

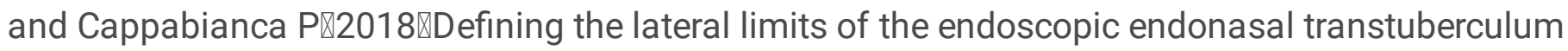
transplanum approach: anatomical study with pertinent quantitative analysis. J Neurosurg130:848860

10. Eloy JA, Murray KP, Friedel ME, Tessema B and Liu JK囚2012هGraduated endoscopic multiangle approach for access to the infratemporal fossa: a cadaveric study with clinical correlates. Otolaryngol Head Neck Surg147:369-78

11. Fernandez-Miranda JC, Zwagerman NT, Abhinav K, Lieber S, Wang EW, Snyderman CH and Gardner PA $₫ 2018 \otimes C$ Cavernous sinus compartments from the endoscopic endonasal approach: anatomical considerations and surgical relevance to adenoma surgery. J Neurosurg129:430-441

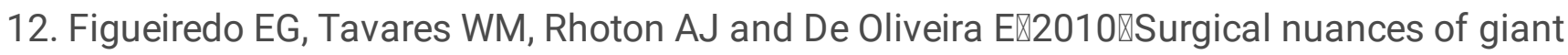
paraclinoid aneurysms. Neurosurg Rev33:27-36 
13. Hartnick CJ, Myseros JS, Myer CR 2001囚Endoscopic access to the infratemporal fossa and skull base: a cadaveric study. Arch Otolaryngol Head Neck Surg127:1325-7

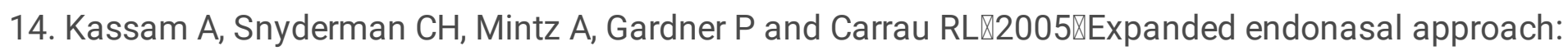
the rostrocaudal axis. Part I. Crista galli to the sella turcica. Neurosurg Focus19:E3

15. Kassam A, Snyderman CH, Mintz A, Gardner P and Carrau RL区2005『Expanded endonasal approach: the rostrocaudal axis. Part II. Posterior clinoids to the foramen magnum. Neurosurg Focus19:E4

16. Laufer I, Anand VK, Schwartz TH $₫ 2007 \otimes E n d o s c o p i c$, endonasal extended transsphenoidal, transplanum transtuberculum approach for resection of suprasellar lesions. J Neurosurg106:400-6

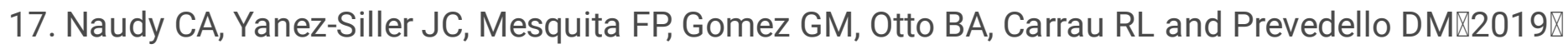
Anatomic Nuances of the Ophthalmic Artery Origin from a Ventral Viewpoint: Considerations and Implications for Endoscopic Endonasal Surgery. Oper Neurosurg (Hagerstown)16:478-485

18. Nozaki K, Kikuta K, Takagi Y, Mineharu Y, Takahashi JA and Hashimoto N囚2008®Effect of early optic canal unroofing on the outcome of visual functions in surgery for meningiomas of the tuberculum sellae and planum sphenoidale. Neurosurgery62:839-44, discussion 844-6

19. Peris-Celda M, Kucukyuruk B, Monroy-Sosa A, Funaki T, Valentine R and Rhoton AJ『2013囚The recesses of the sellar wall of the sphenoid sinus and their intracranial relationships. Neurosurgery73:ons117-31, discussion ons131

20. Puzzilli F, Ruggeri A, Mastronardi L, Agrillo A and Ferrante Lه1999هAnterior clinoidal meningiomas: report of a series of 33 patients operated on through the pterional approach. Neuro Oncol1:188-95

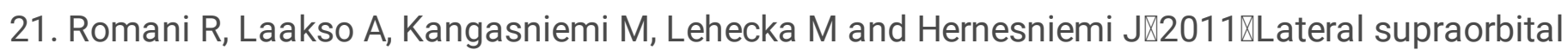
approach applied to anterior clinoidal meningiomas: experience with 73 consecutive patients. Neurosurgery68:1632-47, discussion 1647

22. Russell SM, Benjamin V $\ 2008 \bigotimes$ Medial sphenoid ridge meningiomas: classification, microsurgical anatomy, operative nuances, and long-term surgical outcome in 35 consecutive patients. Neurosurgery62:38-50, discussion 50

23. Tayebi MA, Borba ML, Lawton MT, Eschbacher JM, Belykh EG, Felicella MM and Preul MC $₫ 2019 \rrbracket$ Interdural course of the ophthalmic artery in the optic canal. J Neurosurg132:277-283

24. Theodosopoulos PV, Guthikonda B, Brescia A, Keller JT and Zimmer LA囚2010『Endoscopic approach to the infratemporal fossa: anatomic study. Neurosurgery66:196-202, discussion 202-3

25. Wu X, Xie SH, Tang B, Yang L, Xiao LM, Ding H, Bao YY, Tong ZG and Hong Tه2020®Single-stage endoscopic endonasal approach for the complete removal of trigeminal schwannomas occupying both the middle and posterior fossae. Neurosurg Rev

26. Xiao L, Xie S, Tang B, Hu J and Hong T区2019凶Endoscopic endonasal anterior clinoidectomy: surgical anatomy, technique nuance, and case series. J Neurosurg1-11

\section{Supplementary}

Supplemental Table 1 is not available with this version 


\section{Figures}

\section{Figure 1}

A: Endoscopic endonasal view of our proposed parasuprasellar area and its surrounding essential anatomical structures. The parasuprasellar area is delineated by the yellow quadrangular space, which is limited medially by the medial edge of the MOCR, laterally by the lateral edge of the LOCR, superiorly by the PEA, and inferiorly by the inferior edge of the MOCR and LOCR. In addition, as bounded by the optic nerve, it can be divided into supraoptic and infraoptic regions. B-D: Illustration showing different combinations of surgical modules in both midline (transsellar/transtuberculum/transplanum approach) and/or lateral (transcavernous and parasuprasellar approach) planes. Note that the parasuprasellar approach includes supraoptic and infraoptic approaches. The various combinations of endoscopic corridors are indicated with different quadrangular colors (figure in the lower right corner). Red marks the combination of the endoscopic endonasal midline approach and parasuprasellar approach, blue represents the combination of the transcavernous approach and parasuprasellar approach, green shows the combination of the midline approach, transcavernous approach and parasuprasellar approach. E: Three-dimensional (3D) reconstruction of a postoperative fine-slice CT scan showing the extent of bone removal through the supraoptic and infraoptic approaches. F: Artistic illustration demonstrating maximum bone removal (blue square) in the parasuprasellar area via the supraoptic and infraoptic approach. Eth = cribriform plate of the ethmoid, $\mathrm{PEA}=$ posterior ethmoidal artery, PS = planum sphenoidale, $\mathrm{OC}=$ optic canal, $\mathrm{TS}=$ tuberculum sellae, $\mathrm{MOCR}=$ medial optocarotid recess, $\mathrm{LOCR}=$ lateral optocarotid recess, $\mathrm{CP}=$ carotid protuberance, $\mathrm{CS}=$ cavernous sinus, $\mathrm{CN}$ II = optic nerve, $\mathrm{CN} \mathrm{III}=$ oculomotor nerve, CN IV = trochlear nerve, PcomA = posterior communication artery, Sup.Clid. ICA = supraclinoidal internal carotid artery, PCA = posterior cerebral artery. The figure is available in color only online.

\section{Figure 2}

Endoscopic endonasal supraoptic (EESO) approach: stepwise dissection to the supraoptic region in a colored silicone-injected cadaveric specimen. A: Panoramic view of the sphenoid sinus floor with its anatomical landmarks. The blue quadrangular zone marks the supraoptic region, and the black asterisk represents the supraoptic recess. B: A closer view of the supraoptic region after removal of the medial portion of the lesser sphenoid wing and $\mathrm{OC}$ unroofing. C: After removing the bone and dura mater lateral to the planum sphenoidale, the gyrus rectus, olfactory nerve, medial orbital gyrus, anterior orbital gyrus and post orbital gyrus of the frontal lobes were exposed, viewed with a $0^{\circ}$ endoscope. D: Artistic illustration demonstrating the contents of the supraoptic region that can be reached via the EESO approach. Olf. $\mathrm{N}$ = olfactory nerve, Med.Orb. Gyrus = medial orbital gyrus, Ant.Orb. Gyrus = anterior orbital gyrus, Post.Orb. Gyrus = post orbital gyrus. The figure is available in color only online. 


\section{Figure 3}

Endoscopic endonasal infraraoptic (EEIO) approach: stepwise dissection to the infraoptic region in a colored silicone-injected cadaveric specimen. A: The main anatomical landmarks in the infraoptic region (blue zone) are shown. B: Removal of the anterior wall of the $\mathrm{OC}$ in a medial-lateral direction up the orbit apex. C: The dura overlying the intracranial ON was incised longitudinally to expose the origin of the OA, the diaphragm was incised toward the medial part of the DDR, and SHA and its branches were exposed. D: A closer view shows more subdural contents, including the PcomA, OT and A1 segments of the anterior cerebral artery. E: Drilling of the optic strut and showing the ACP triangle. F: The DDR and ON sheath are opened to further safely dissociate the $\mathrm{OA}$ and $\mathrm{ON}$. G and $\mathrm{H}$ : The subdural neurovascular structures were explored again by gently lifting of the ipsilateral ON. The main structures are identified, including the PcomA, pituitary stalk, AchA and its branches (black plus sign) into the anterior perforating substance in the crural cistern, the CNIII passing between the PCA and SCA into the cavernous sinus, and the bifurcation of the ICA. I: The base and tip of the ACP can be further removed by gentle lifting of the OA or medial mobilization of the paraclinoidal ICA. J: The ACP triangular is further enlarged. K: The sylvian cistern was visible, and the ICA bifurcation was exposed between the frontal and temporal lobes, more laterally, the middle cerebral artery (MCA) bifurcation was observed at the level of its insular portion. $\mathrm{L}$ : The OA was transected, and the operation space of the EEIO corridor was further enlarged. M: Artistic illustration showing the main contents of the infraoptic region that can be reached via the EEIO approach. Note the $\mathrm{ON}$ has been slightly elevated. $\mathrm{ON}=$ optic nerve, $\mathrm{OA}=$ ophthalmic artery, SHA = superior hypophyseal artery, D.D.R = distal dural ring, P.D.R = proximal dural ring, ICA = internal carotid artery, OT = optic tract, AchA = anterior choroidal artery, SCA = superior cerebellar artery, Orb.Fr.A = orbital frontal artery, $\mathrm{ACP}=$ anterior clinoid process, $\mathrm{M} 1$ = sphenoidal segment of the middle cerebral artery, $\mathrm{M} 2=$ insular segment of the middle cerebral artery. The figure is available in color only online.

\section{Figure 4}

The instruments demonstrating a combined supraoptic and infraoptic approach to access the parasuprasellar area. The figure is available in color only online.

\section{Figure 5}

Case 1, a 56-year-old woman, presented with a 1-year history of dizziness and progressive left visual loss for more than 1 month. A: Preoperative coronal Gd-enhanced MRI showing a left ACP meningioma. B-E: Intraoperative images. B: Exposure of the lateral dura of the planum sphenoidale and supraoptic recess (black asterisk). C: Drilling the roof wall of the optic canal and supraoptic recess in a medial-to-lateral direction toward the body of the lesser sphenoid wing. D: Separation of the tumor from the olfactory 
nerve through the supraoptic approach. E: Final endoscopic view after complete tumor removal. The white arrow represents the severed posterior ethmoidal artery. F: Postoperative coronal MRI showing total tumor removal. The yellow arrow represents the autologous fat used during the operation. $+=$ tumor cavity. The figure is available in color only online.

\section{Figure 6}

Case 10, a 62-year-old woman, presented with visual loss for 2 months. A and B: Preoperative CT angiography (A) and a 3-D reconstruction image (B) showing an Acom aneurysm (An1), a left praclinoid aneurysm (An2), and a large right paraclinoid aneurysm (An3). C and D: Anteroposterior view (C) and lateral view (D) of bilateral internal carotid artery (ICA) injection of digital subtraction angiography (DSA) confirming an Acom aneurysm, a left praclinoid aneurysm, and a large right paraclinoid aneurysm. E-J: Intraoperative images. E: Endoscopic view of the skull base showing important bony landmarks. F and G: Intraoperative image demonstrating an aneurysm body with a thrombus above the right optic nerve that cannot be clipped through an endonasal approach. $\mathrm{H}$ and $\mathrm{I}$ : Exposure to the Acom aneurysm $(\mathrm{H})$ and left paraclinoid aneurysm (I). J: Intraoperative picture showing that both aneurysms were clipped successfully after proximal control. K: Postoperative CT angiography confirmed the patency of the bilateral $A 2$ and distal ICA. $L$ and M: Postoperative lateral view $(L)$ and anteroposterior view (M) of left ICA injection of DSA, revealing complete obliteration of An1 and An2. N: Postoperative anteroposterior view of right ICA injection of DSA, showing complete obliteration of the An3 after second-stage coiling. An = aneurysm, R.OA = right ophthalmic artery, L.OA = left ophthalmic artery, $\mathrm{Ch}=$ optic chiasm. The figure is available in color only online.

\section{Figure 7}

Case 2, A 25-year-old woman presented with headache and decreased vision in her right eye for 6 months. A: Preoperative coronal Gd-enhanced MRI demonstrating a right recurrent ACP meningioma. B: Removal of the tumor on the medial and upper parts of the supraclinoidal ICA. C and D: Removal of the ACP invaded by the tumor. E: Separation of tumor adhering to the bifurcation of the ICA through the infraoptic corridor. F: Postoperative MRI showing total tumor removal. Tu = tumor, Ps = pituitary stalk, $\mathrm{ACP}=$ anterior clinoid process. Some panels (Fig. 7A, D and F) of the figure have been published in Journal of Neurosurgery. Published with permission. The figure is available in color only online.

\section{Figure 8}

Case 9, a 47-year-old woman, presented with headache for 3 months. A: Preoperative lateral view of left internal carotid artery (ICA) injection for digital subtraction angiography (DSA) showing an ophthalmic aneurysm (An1) and a paraclinoid aneurysm (An2). B: anteroposterior view of the 3D reconstruction 
images showing another aneurysm (An3) located in the cavernous segment of the ICA. C-G: Intraoperative images. C: Exposure of the paraclival ICA for proximal control in advance. D: Removal of the ACP tip. E: Temporary occlusion of the OA. F: Exposure of the An2 neck by lifting the ipsilateral optic nerve. G: Clip application to the An2 neck after proximal control. H: Intraoperative visual evoked potential monitoring changed after temporary occlusion of the OA. I: Postoperative lateral view of DSA showing complete obliteration of An1 and An2. Some panels (Fig 8A, B, G and I) of the figure have been published in Journal of Neurosurgery. Published with permission. The figure is available in color only online.

\section{Figure 9}

Case 4, a 37-year-old woman, presented with progressive visual loss in the left eye for 2 years. A: Preoperative coronal Gd-enhanced MRI showing a left recurrent ACP meningioma involving the right cavernous sinus and encasement of the ICA and its bifurcation. B囚Preoperative CT scans. The yellow arrow indicates the hyperplastic ACP. C: Preoperative lateral view of left ICA injection of digital subtraction angiography (DSA) showing that the ophthalmic artery was not visible. D-L: Intraoperative images. D: Endoscopic view of important bony landmarks after the initial transpterygoid approach. E: Exposure of the thickened OC and drilling of its roof and anterior walls. F: Endoscopic exposure of the ACP triangle. The red dotted line indicates the course of the imaginary occluded OA. G: Sacrifice of the OA surrounded by tumors and involving the dura. $\mathrm{H}$ : Removal of the hyperplastic ACP. I-K: Resection of the tumor on the medial and lateral sides of the supraclinoidal ICA through the combined supraoptic and infraoptic approaches. L: Endoscopic exposure of the bifurcation of the ICA covered by arachnoid membrane. M: Corresponding postoperative coronal MRI showing subtotal tumor resection, with part of the tumor remaining in the lateral wall of the left CS. N: Postoperative CT scan showing ACP resection. The white arrow represents the removed ACP. Some panels (Fig 9A, B, M and N) of the figure have been published in Journal of Neurosurgery. Published with permission. The figure is available in color only online.

\section{Figure 10}

Case 11, a 30-year-old man, presented with progressive loss of vision for 6 months. A: Preoperative coronal Gd-enhanced MRI demonstrating a recurrent intra- and suprasellar craniopharyngioma with right sylvian fissure extension. B-H: Intraoperative images. B: Endoscopic view of the skull base showing important bony landmarks. The white asterisk marks the supraoptic recess. C: Removal of intrasellar tumor. D: Extracapsular separation of the tumor adhering to the frontal lobe through the supraoptic corridor. E: Endoscopic view of the sylvian fissure during tumor removal. F and G: Sharp dissection of the tumor away from the neurovascular structures by the infraoptic corridor. $\mathrm{H}$ : Final endoscopic view after complete tumor removal. I: Postoperative coronal MRI showing total tumor removal. The figure is available in color only online. 


\section{Figure 11}

Case 6, a 45-year-old woman presented with visual loss and headache for 2 years. A-C: Preoperative Gdenhanced MRI showing a multilobulated pituitary adenoma with bilateral cavernous sinus invasion, inferior extension into the clivus, superior compressed the third ventricle, and significantly encasement of the ICA and its bifurcation. D-I: Intraoperative images. D: Opening of the optic nerve sheath. E and F: Removal of the tumor below the right optic nerve using a bimanual microsurgical technique and endoscopic view after resection. G: Expose the tumor above the optic nerve. H: Removal of the tumor using angled suction instruments through the supraoptic corridor. The red dotted line indicates the course of the A1 segments of the anterior cerebral artery. I: Endoscopic view after tumor resection. J-K:

Postoperative MRI showing total tumor removal. The yellow arrow represents the normal pituitary gland. * $=$ optic nerve sheath,$+=$ tumor cavity. The figure is available in color only online. 